\title{
O TRABALHO EM SAÚDE NO CONTEXTO HOSPITALAR: PROCESSOS E NECESSIDADES COMO SUBSÍDIOS PARA A FORMAÇÃO PROFISSIONAL
}

\author{
The work in health in the hospital context: \\ Process and needs as benefities for the professional formation \\ El trabajo en salud en el contexto hospitalario: \\ Procesos y necesidades como subsidio para la formación profesional
}

Isa Maria Nunes

Antenor Amâncio Filho
Maria Aparecida Vasconcelos Moura

José Luiz Telles

\begin{abstract}
Resumo
Apresenta reflexão teórica sobre o processo de trabalho em saúde e a contribuição do pensamento Marxista, para a temática. Parte da constatação de que esse processo é social, se conforma e se legitima na realização de trabalhos, ao mesmo tempo especializados e coletivos, fundamentados nos saberes dos profissionais envolvidos. Expõe elementos do processo de trabalho em saúde e discute a sua caracterização nos serviços de saúde, principalmente no contexto hospitalar. As contradições desse processo são realçadas, constatando-se que o mesmo tem-se conformado em um círculo de retroalimentação e apresentado dificuldades para identificar e responder às necessidades tanto da população quanto dos profissionais de saúde. Estes agentes precisam ser visibilizados como sujeitos históricos, ativos e inseridos em um contexto de trabalho permeado por dilemas e conflitos, vislumbrando-se, por meio de processos de formação profissional e inserção mais afinados com a realidade, a construção de relações de trabalho mais harmoniosas.
\end{abstract}

Palavras-chave: Processo de trabalho. Profissionais de saúde. Serviços Hospitalares.

\begin{abstract}
This study presents a theoretical reflection about the work process in health, based on Marxist thought. The study illustrates the hypothesis that this social construction legitimizes itself through the accomplishment of each specialized practice. The study is based on the technical and practical knowledge of the professionals involved. This study shows the elements of the work process in the context of institutionalized assistance, mainly in the hospital environment. It discusses the repercussion of the capitalist production model on the organization of health services. The contradictions of this process are highlighted and there is evidence that this process has resigned itself in a retrofeeding cycle and has shown difficulties to identify and answer to the needs, not only of the population, but also of the health professionals. These agents need to be seen as historical subjects who are active and are inserted in a work context where there are dilemmas and conflicts and where it is possible to envision through processes of formation and inclusion more attuned with reality, the construction of healthier relationships at work.
\end{abstract}

\section{Resumen}

Este estudio presenta una reflexión teórica sobre el proceso de trabajo en salud a partir de la contribución del pensamiento Marxista. El punto de partida és el entendimiento de que esa construcción social se legaliza en la realización de cada trabajo especializado, proveniente del saber técnico y práctico de los profesionales involuerados. Expone elementos del proceso de trabajo en el contexto de la asistencia institucionalizada, principalmente en el ambiente hospitalario; discute las repercusiones del modelo capitalista de producción sobre la organización de los servicios de salud. Las contradicciones de ese proceso son resaltadas, constatándose que el mismo, se ha conformado en un círculo de retroalimentación, presentando dificultades para identificar y responder a las necesidades tanto de la población, como de los profesionales de salud. Estos agentes necesitan ser visibilizados como sujetos históricos, activos e incluidos en el contexto de trabajo de donde surgen dilemas y conflictos, siendo posible vislumbrar, por medio de procesos de formación e inclusión más ajustados a la realidad, la construcción de relaciones de trabajo más saludables.
Keywords:

Work process. Health professionals. Hospital Services.
Palabras clave:

Proceso de trabajo. Profesionales de salud. Servicios Hospitalarios. 


\section{INTRODUÇÃO}

0 trabalho é um processo em que os seres humanos atuam sobre as forças da natureza, submetendoas ao seu controle e transformando os recursos naturais em formas úteis à sua existência. 0 processo de trabalho aqui considerado pauta-se na concepção marxista, expressão que se refere aos conceitos formulados por Karl Marx e que designa um amplo movimento de idéias ${ }^{1}$.

Com efeito, Marx distingue três componentes do processo de trabalho, a saber: a) a atividade adequada a um fim, isto é, a ação laboral propriamente dita; b) o objeto de trabalho, a matéria sobre a qual se aplica o trabalho e; c) os meios de trabalho ou instrumentos (ferramentas) ${ }^{2}$.

0 processo de trabalho pode ainda ser entendido como o modo como o homem produz e reproduz sua existência. Ao fazê-lo, estabelece relações sociais e objetiva sua subjetividade. A concepção histórica, materialista e dialética procura demonstrar que cada geração transmite uma massa de forças produtivas, de capitais e de circunstâncias, que é, por um lado, muito modificada pela nova geração, mas, por outro, dita-lhe suas condições de existência e lhe imprime um desenvolvimento determinado, um caráter específico. Conseqüentemente, as circunstâncias fazem os homens, da mesma forma que os homens fazem as circunstâncias 3:18.

$\mathrm{Na}$ perspectiva de análise sob a ótica aqui focalizada, merecem destaque na produção da teórica brasileira os estudos de Mendes-Gonçalves, ${ }^{4,5}$ que tratam da aplicação da teoria marxista do trabalho ao campo da saúde e a conformação dos elementos constituintes do processo de trabalho (objeto, instrumentos e agentes), e estudos que buscam aprofundar o conhecimento da subtotalidade representada pelo trabalhador no processo de trabalho.

No caso do trabalho em saúde, há que se considerar também dois aspectos essenciais que interferem nesse processo, que se organiza de forma a atender as diferentes situações e necessidades da clientela e, ao mesmo tempo, considerar os valores e as regras postas para o trabalho ${ }^{6}$. Requer também o reconhecimento de que as atividades executadas pelos distintos profissionais se pautam em uma construção social que se legitima a partir da realização de cada trabalho especializado, fundamentado em saberes técnicos e práticos.

Entretanto, o desenvolvimento deste trabalho depende da participação de diversos atores e seus respectivos trabalhos, a exemplo de: laboratório, almoxarifado, lavanderia, setor de exames radiográficos, setor de enfermagem, setor médico, administração, entre outros. As ações necessárias para a prestação de serviços de saúde são realizadas coletivamente, e a abstração da finalidade/intencionalidade do processo de trabalho tende a ser elaborada a partir do que os agentes do trabalho identificam como necessidade de transformação no objeto de trabalho.

Assim, no âmbito das necessidades, são reconhecidas demandas tanto dos profissionais da área quanto da população usuária dos serviços de saúde. A obtenção do equilíbrio entre estes dois aspectos implica reais possibilidades de que seja alcançada maior qualidade nos serviços prestados.

Tomando esse pressuposto como ponto de partida, o presente ensaio visa refletir sobre alguns elementos do processo de trabalho em saúde, suas contradições e interrelação com as necessidades tanto dos usuários quanto dos profissionais no tocante à sua formação.

\section{PROCESSOS DE TRABALHO E NECESSIDADES DE USUÁRIOS: APROXIMAÇÕES CONTRADITÓRIAS}

0 trabalho em saúde, mesmo quando dirigido às necessidades da população, reflete a forma de produção/organização dos instrumentos de trabalho em geral, os quais, por sua vez, subordinam-se aos ditames das circunstâncias políticas, seja na macro ou na micro esfera de sua interferência.

0 aprofundamento dos estudos sobre 0 tema permite afirmar ser este um assunto bastante conhecido e discutido. No tocante ao tema "necessidades de saúde", diferentes caminhos têm sido tomados na tentativa de conceituação. Reconhecer a complexidade e a multiplicidade de enfoques é tão fundamental quanto entender a sua íntima relação com a organização dos serviços e a conformação geral de sua estrutura, a qual se apresenta como demanda para os serviços de saúde, sendo que a origem dessa busca é o carecimento, algo que o indivíduo entende que deve ser corrigido em seu atual estado sociovital. Pode ser uma alteração física, orgânica, que o impede de seguir vivendo em sua rotina de vida, ou um sofrimento ainda não identificado fisicamente; ou até mesmo uma situação que reconhece como "uma falta", algo de que carece, como, por exemplo, uma informação 4:12.

A idéia da antevisão do produto do trabalho humano remete ao reconhecimento de algum tipo de demanda, de carecimento, para o qual se enxerga uma correção/ satisfação. Estabelece-se, então, uma necessidade, geradora de intervenções, as quais também se apresentam como necessidades, criando o ciclo vicioso. 
A realização do trabalho na saúde implica uma relação muito próxima entre os profissionais e os usuários, exigindo elevada capacidade de percepção, compreensão e compartilhamento das demandas que se apresentam como necessidades, nem sempre explicitadas. A partir dessas demandas, constrói-se o objetivo ou finalidade da ação profissional, a qual se reparte em muitas e diversificadas intervenções e interações entre os trabalhadores dos serviços de saúde e seus respectivos instrumentos de trabalho.

Uma visão dialética da necessidade em saúde obriga a reconhecer o caráter social tanto das necessidades quanto dos processos criados para atendê-las, e exige reafirmar que os carecimentos são criados e recriados na vida em sociedade, podendo, portando, diferir em razão do grupo, do local e do tempo. Pode ser de uma, de várias ou de todas as pessoas, e pode, inclusive, resultar de manipulação ideológica e política ?

Em uma outra vertente, reconhece-se que, na assistência à saúde, há um encontro de necessidades; pode-se dizer:

um espaço intercessor entre usuário e trabalhador produtor do ato (e isto vale mesmo para as ações coletivas de saúde, para não ficarmos com a imagem de que só existe nos momentos individualizados), no qual 0 trabalhador vem instituindo necessidades e modos capturados (e em processo de "captura") de agir, e o usuário também. Neste momento, temos um encontro e uma negociação, em ato, dos encontros e necessidades $8: 57$.

Independentemente da categoria profissional, os profissionais da saúde vêm se deparando com demandas a cada dia mais complexas do ser humano. 0 trabalho vem absorvendo transformações rápidas e ",para sobreviver neste novo mundo do trabalho, o trabalhador tem de, necessariamente, se apropriar de outras áreas do conhecimento, e não apenas daquela de sua formação original" 9:22.

Mas este ainda não parece ser o enfoque privilegiado do processo de trabalho hospitalar, haja vista o elenco de necessidades que estão ligadas ao próprio processo de trabalho no serviço de saúde. Esta conformação atende a um paradigma que privilegia o controle, a vigilância e a relação de subordinação à instituição sob a forma de formulários, mapas, escalas, relatórios, normas e rotinas, às quais estão submetidos profissionais e usuários, entendidos ora na função de meios de trabalho, ora como ação que tem finalidade em si própria.

\section{PROCESSO DE TRABALHO EM SAÚDE: ELEMENTOS E CONTEXTOS DA PRÁTICA E DA FORMAÇÃO}

A delimitação da finalidade do trabalho em saúde, como prática histórica e socialmente determinada, implica 0 resgate, por parte dos sujeitos, de suas concepções individuais sobre saúde-doença, as quais expressam dimensões biológicas, sociais, afetivas e culturais, embutidas no fazer próprio de cada categoria profissional, na dependência do tipo de espaço onde esteja atuando, de modo que a - suposta - transformação pretendida se dilui de tal forma que os esforços empenhados parecem apontar para várias direções, por caminhos diferentes, até contrários, em alguns casos.

Para garantir a implementação de ações complementares que viabilizem a atenção integral na prestação de serviços de saúde, o alcance da assistência pretendida pressupõe a visão clara da finalidade do trabalho de todos os profissionais envolvidos. Mesmo considerando que a assistência à saúde, em sua forma institucionalizada, pressupõe a divisão do trabalho, é preciso reafirmar que:

a distribuição do trabalho em tarefas dificulta o envolvimento dos membros da equipe na percepção do cliente como um todo, quando não vem prejudicar também a motivação do profissional para o trabalho, tornando-o monótono, repetitivo e cansativo (Rocha et. al. ${ }^{10: 241}$ ).

Essa realidade mostra-se mais claramente na rígida hierarquia do trabalho no ambiente hospitalar, em especial, pela especificidade desse espaço, sendo necessário tê-la como pano-de-fundo para entender a articulação entre os instrumentos e a finalidade do processo de trabalho, no âmbito microinstitucional, no cotidiano, vislumbrando a possibilidade de que, com a articulação desses elementos, seja construída a especificidade desse trabalho. Isto nos remete a Schraiber et al.$^{11}$, quando afirma que o trabalho em equipe é:

o trabalho que se compartilha, negociando-se as distintas necessidades de decisões técnicas, uma vez que seus saberes operantes particulares levam às bases distintas de julgamentos $e$ de tomadas de decisões quanto à assistência ou cuidados a se prestar.

A exigência da valorização do trabalho em equipe e da recomposição das ações surge em decorrência de mudanças na oferta de serviços: não somente a especialização do trabalho e a crescente incorporação 
da tecnologia, mas também a diretriz política da atenção integral às necessidades de saúde e 0 reconhecimento do caráter interdisciplinar dos objetos de trabalho em saúde.

0 trabalho em equipe não pressupõe abolir as especificidades dos trabalhos, pois as diferenças técnicas expressam a possibilidade de contribuição da divisão do trabalho para a melhoria dos serviços prestados, à medida que a especialidade permite aprimoramento do conhecimento e do desempenho técnico em determinada área de atuação, bem como maior produção. Os profissionais de saúde destacam a necessidade de preservar as especificidades de cada trabalho especializado, o que implica manter as diferenças técnicas correlatas ${ }^{12}$.

Consoante com a idéia de que a finalidade do trabalho determina os meios/instrumentos a serem usados, cabe refletir que estes traduzem as condições sociais sobre as quais se realiza o trabalho em um dado período histórico.

0 contexto do trabalho em saúde, por vezes desfavorável tanto para os profissionais quanto para a população atendida, reflete as mudanças decorrentes da implementação de políticas que privilegiam 0 atendimento às exigências de um modelo econômico expropriador dos direitos, do prazer e da criatividade do trabalhador, resultando em um quadro preocupante.

Com os sucessivos ajustes econômicos, desde o final da década de oitenta, e início dos anos noventa, as instituições de saúde, embora tardiamente, tiveram que se adaptar aos novos tempos e passaram a utilizar-se, ainda que timidamente, dos métodos empregados no setor produtivo, como a terceirização de algumas atividades, o enxugamento de estoques de materiais, a reciclagem de materiais, buscando uma redução de custos e um equilíbrio entre receitas e despesa ${ }^{\text {9: }}$.

Está posto que o modo de organização dos elementos do processo de trabalho dos profissionais de saúde estabelece íntima relação com a qualidade do atendimento requerido pelos usuários. Entretanto, os agentes dos serviços, em especial no âmbito público, convivem com situações que denunciam a relevância dessa problemática, na medida em que os prestadores de serviços de saúde enfrentam dificuldades de diferentes ordens e que, em última instância, a qualidade da assistência fica comprometida.

No âmbito do Sistema Único de Saúde (SUS), aliase a esta realidade, na composição do contingente de pessoal, a falácia da chamada "flexibilização" das relações entre empregado e empregador, usada como artifício para driblar a legislação trabalhista por meio, por exemplo, de contratações temporárias e da criação de diferentes categorias de "estagiários". Esses recursos são cada vez mais utilizados para manter quadros mínimos de pessoal, sem que o poder público se responsabilize pelos custos dos direitos trabalhistas, com o agravante da adoção desse tipo de política de recursos humanos inclusive na área da saúde.

Disto resulta a constatação de que os profissionais de saúde convivem com problemas crescentes nas relações de trabalho, muitas vezes com redução da garantia dos meios/instrumentos considerados essenciais para a realização do seu trabalho em condições seguras.

Cabe aqui situar o processo de precarização do trabalho como sendo um processo central, comandado pelas exigências tecnológico-econômicas da evolução do capitalismo moderno. É o fenômeno que suscita uma nova questão social, cujo núcleo seria novamente, tal qual o pauperismo foi na primeira metade do século XIX, a existência de "inúteis para o mundo e, em torno deles, de uma nebulosa de situações marcadas pela instabilidade e pela incerteza do amanhã, que atestam o crescimento de uma vulnerabilidade de massa" ${ }^{13: 593 .}$.

Contraditoriamente, o processo de trabalho, que deveria se conformar para libertar todos os envolvidos, se coloca então a serviço de uma lógica voltada para responder e retroalimentar o próprio processo de trabalho, permitindo situações nas quais o atendimento a alguma demanda que fuja à rotina se transforma em uma excepcionalidade, ou mesmo uma concessão. É o que pode ocorrer quando o trabalhador se utiliza de meios não convencionais, quando estabelece novas formas de relação com o usuário ou quando se arrisca na tentativa de dar visibilidade à sua intuição, criatividade e sensibilidade.

\section{CONCLUSÃO}

Tratar das contradições do processo de trabalho em saúde, do ponto de vista tanto da inserção dos profissionais no mercado de trabalho quanto - e antes da sua formação, constitui-se em desafio para todos os que se preocupam com a temática. Impõe-se que a discussão seja enfrentada em uma perspectiva contextualizada, questionando, analisando e revendo as concepções práticas, os compromissos e as escolhas teórico-metodológicas nesta formação.

No entanto, a transformação na lógica da formação dos profissionais na área da saúde, por si só, não 
garante mudanças na qualidade dos serviços oferecidos à população. Esta assistência assume uma complexidade que vai além da qualidade dos profissionais que a executam. Assumem relevância sobre a prestação dos serviços nas instituições "as determinações das grandes políticas socioeconômicas, que por sua vez, definem o valor e o eixo das políticas de saúde, no contexto do projeto neoliberal", ressalta Sordi et al. ${ }^{14: 87}$.

Urge, portanto, que nos ocupemos em promover, no micro e no macrocontexto do trabalho, oportunidades educativas que resgatem valores e práticas tidas, por vezes, como defasadas, mas que dão importante contribuição para a organização de um tra-

\section{Referências}

1. Gianotti JA. Karl Marx: vida e obra.. São Paulo (SP): Nova Cultural; 1999. p. 201-10. ( Coleção Os pensadores)

2. Marx K. 0 capital. $14^{\mathrm{a}}$ ed. São Paulo (SP): Bertrand Brasil; 1994. v.l.

3. Almeida MCP, Rocha SMM. 0 trabalho de enfermagem. São Paulo (SP): Cortez; 1997.

4. Mendes Gonçalves RB. Práticas de saúde: processos de trabalho e necessidades. São Paulo (SP): Secretaria Municipal da Saúde/Centro de Formação dos Trabalhadores em Saúde; 1992.

5. Mendes Gonçalves RB, Schraiber LB. Seis teses sobre a ação programática em saúde In: Programação em Saúde Hoje. São Paulo (SP): HUCITEC; 1993.

6. Peduzzi M, Anselmi ML. 0 processo de trabalho do auxiliar de enfermagem In: Ministério da Saúde(BR). Secretaria de Gestão do Trabalho e da Educação na Saúde. Projeto de Profissionalização dos Trabalhadores da Área de Enfermagem. Brasília (DF); 2003.

7. Schraiber LB, Mendes Gonçalves RB. Necessidades de saúde e atenção primária. Saúde do adulto. Programas e ações na Unidade Básica. São Paulo (SP): HUCITEC; 1996.

8. Merhy EE, organizador Agir em saúde: um desafio para o público. Rio de Janeiro (RJ): HUCITEC/Buenos Aires (AR): Lugar Editorial; 1997.

9. Cocco MIM. Trabalho e educação: novas possibilidades para antigos problemas. In: Bagnato MH. Educação, saúde e trabalho. São Paulo (SP): Alínea; 1999.

10. Rocha JBB, Nogueira LT, Zeitoune RCG. Entre o prescrito e o real: (des)compasso entre ensino e prática do técnico de enfermagem. Esc Anna Nery Rev Enferm 2005 ago; 9 (2): 237 - 46.

11.Schraiber LBetal. Planejamento, gestão e avaliação em saúde: identificando problemas. Rev. Ciência \& Saúde Coletiva 1999; (4): 221 - 42. balho que esteja consoante com as características da clientela. A meta deve ser a de garantir que o processo de formação e a inserção seja conduzido a partir de referenciais e pressupostos mais afinados com a realidade e as relações sociais atuais nas suas vertentes culturais, espirituais e econômicas, para que seja possível superar as dificuldades até aqui delineadas.

É nesse contexto que a reflexão da categoria "trabalho" em Marx pode trazer subsídios para uma reflexão sobre o processo de trabalho em saúde, buscando-se uma compreensão mais apropriada sobre sua complexidade na realidade brasileira.

12.Peduzzi M. Equipe multiprofissional de saúde: conceito e tipologia. Rev Saúde Pública 2001 fev; 35 (1): 103-09.

13.Castel R. As metamorfoses da questão social: uma crônica do salário. Petrópolis (RJ): Vozes;1998.

14.Sordi MRL, Bagnato MHS. Subsídios para uma formação profissional crítico-reflexiva na área da saúde: o desafio da virada do século. Rev. Latino-Am Enfermagem, 1998 abr; 6 (2): 83-88.

\section{Sobre os Autores}

\section{Isa Maria Nunes}

Escola de Enfermagem / Universidade Federal da Bahia.

Bahia - e-mail: isam@ufba.br

\section{Maria Aparecida Vasconcelos Moura}

Escola de Enfermagem Anna Nery / UFRJ. Rio de Janeiro.

\section{Antenor Amâncio Filho}

Escola Nacional de Saúde Pública / FIOCRUZ.

Rio de Janeiro.

\section{José Luiz Telles}

Escola Nacional de Saúde Pública / FIOCRUZ.

Rio de Janeiro 